\title{
ARTIGOS
}

Submetido em 12.04.2016. Aprovado em 07.12.2016

Avaliado pelo processo de double blind Review. Editor Científico: Maurício Reinert

DOI:http://dx.doi.org/10.1590/So034-759020170503

\section{ORGANIZING: COMPREENDENDO INTERAÇÕES E PRÁTICAS DO GRUPO GALPÃO}

\author{
Organizing: Understanding interactions and practices of Grupo Galpão \\ Organizing: Comprendiendo interacciones y prácticas del Grupo Galpão
}

\section{MÍRIAM DE CASTRO POSSAS miriampossas@gmail.com Professora da Universidade Estadual de Minas Gerais, Faculdade de Políticas Públicas - Belo Horizonte - MG, Brasil}

\section{CÍNTIA RODRIGUES DE OLIVEIRA} MEDEIROS

cintia@ufu.br

Professora da Universidade Federal de Uberlândia, Faculdade de Gestão e Negócios -

Uberlândia-MG, Brasil

\section{VALDIR MACHADOVALADÃO}

\section{JÚNIOR}

valdirjr@ufu.br

Professor da Universidade Federal de Uberlândia, Faculdade de Gestão e Negócios - Uberlândia $M G$, Brasil

\section{RESUMO}

Neste artigo, analisamos o Grupo Galpão com o objetivo de compreender como esse grupo teatral se organiza, como resultado de práticas e processos. Para empreender essa tarefa, utilizamos a análise de documentos, entrevistas e observações e analisamos quatro dicotomias presentes no constante organizar do Grupo Galpão: Informalidade/Formalidade, Fragmentação/Centralização, Horizontalidade/ Verticalidade, Expansão/Recolhimento. Como resultados, observamos que há uma tentativa de formalização dos processos, centralização das funções, verticalização das decisões e expansão do grupo. PALAVRAS-CHAVE | Práticas organizacionais, organizing, cultura organizacional, interações, shadowing.

\section{ABSTRACT}

We aim to analyze Grupo Galpão in order to reveal how this theater group is organized based on practices and processes. For this, we conduct the analysis of documents, interviews, and observations, and further examine the four dichotomies present in the constant organization of the Grupo Galpão practices: Informality/Formality, Fragmentation/Centralization, Horizontality/Verticality, and Collection/Expansion. As a result, we observe that there is an attempt to formalize the processes, centralize the functions, verticalize the decisions, and expand the group.

KEYWORDS / Organizational practices, organizing, organizational culture, interactions, shadowing.

\section{RESUMEN}

En este artículo, analizamos al Grupo Galpão con el objetivo de comprender cómo el grupo teatral se organiza como resultado de prácticas y procesos. Para emprender esa tarea, utilizamos el análisis de documentos, entrevistas y observaciones, y analizamos cuatro dicotomías presentes en la organización del Grupo Galpão: Informalidad/Formalidad, Fragmentación/Centralización, Horizontalidad/Verticalidad, Expansión/Concentración. Como resultado, observamos que existe una tentativa de formalización de los procesos, centralización de las funciones, verticalización de las decisiones y expansión del grupo.

PALABRAS CLAVE / Prácticas organizacionales, organizing, cultura organizacional, interacciones, shadowing. 


\section{INTRODUÇÃO}

Neste artigo, concentramos nosso esforço para compreender questões que envolvem o entendimento do que sejam as organizações, objeto de estudo do campo dos estudos organizacionais. Questões diversas (0 que é uma organização? Organizações seriam possíveis sem as interações das pessoas? Seriam elas entidades fixas e estáveis? E, se não o são, como fazer para compreendê-las?) desafiam o campo, e, não raro, estudiosos (Bakken \& Hernes, 2006; Clegg, Kornberger, \& Rhodes, 2005; Czarniawska, 2013; Hatch, 1999; Latour, 2011; Schatzki, 2005; Tsoukas \& Chia, 2002; Weick, 1973) lançam seu olhar para respondê-las, oferecendo conceituações novas de termos até então consagrados na literatura tradicional.

Muitas das respostas às questões anteriormente citadas contradizem o conhecimento acumulado nas teorias organizacionais tradicionais, nas quais a organização é entendida como um conjunto de pessoas que compartilham um objetivo comum e usam a organização como um meio para atingi-lo (Czarniawska, 2013). Ao focar o desempenho organizacional, entende-se que a organização é algo fixo, estável e concreto. A palavra organização ganhou tanta força que passou a ser entendida como uma entidade que pensa, que age e que toma decisões (Peci, 2003), ou seja, reificamos as organizações e as desvinculamos das ações humanas. Nesse sentido, as teorias tradicionais se distanciaram dos estudos que enfocam as pessoas e seus afazeres cotidianos (Santos \& Alcadipani, 2015).

As organizações passam a ser entendidas como processos (Weick, 1973), pois são estes que, continuamente executados, dão origem à organização, que é resultado de uma construção constante dos atores (Czarniawska, 2008b). Repetidas diariamente, com certa constância, essas ações nos passam a sensação de estabilidade, de ordem, de organização (Tsoukas \& Chia, 2002).

$\mathrm{Na}$ tentativa de lançar esse olhar para as organizações e entender a organização na perspectiva do organizing, nesta pesquisa, analisamos o Grupo Galpão, com a finalidade de compreendê-lo como resultado de suas práticas e processos. Os procedimentos metodológicos se orientam pela abordagem qualitativa, utilizando entrevistas semiestruturadas, análise de documentos e a técnica de shadowing. Com isso, pretendemos contribuir com o campo dos Estudos Organizacionais ao considerar um objeto de pesquisa ainda pouco explorado pela Administração, mas de grande relevância sociocultural, que são os grupos teatrais, para questionar as formas mais tradicionais de estudar organizações, ampliando os estudos sobre organizing, que ainda são escassos no contexto brasileiro, além da utilização do shadowing como técnica de pesquisa, tendo em vista sua parca utilização nos estudos brasileiros.

Inicialmente, apresentamos a revisão da literatura sobre organizing. Na sequência, apresentamos os procedimentos metodológicos da pesquisa e os resultados alcançados, seguidos das considerações finais.

\section{A ABORDAGEM DO ORGANIZING PARA A ANÁLISE DAS ORGANIZAÇÕES}

Segundo Czarniawska (2006), na década de 1960, houve uma transição da teoria da Administração para a teoria da Organização, sendo essa mudança resultante de uma corrente, na época, emergente das Ciências Naturais, o behaviorismo. Essa corrente, marcadamente positivista, trouxe um legado das Ciências Naturais para o estudo das Organizações, o que é possível perceber com o advento das duas abordagens que exerceram certa predominância: mecânica e orgânica (Morgan, 1980).

Ambas as abordagens entendem a organização como um sistema composto de partes mecânicas ou orgânicas, e, consequentemente, focam seus estudos em sua estrutura e nas partes que a compõem. Essa mudança fez com que a Administração deixasse de ser vista como uma teoria da ação e passasse a ser entendida como uma teoria de algo que existe independentemente da ação humana (Czarniawska, 2013; Peci, 2003; Santos \& Alcadipani, 2015).

A atenção das teorias organizacionais voltou-se para o desempenho e a eficiência dessa estrutura e sua adaptação aos estímulos do ambiente externo, descrito, geralmente, como estável e simples (Clegg et al., 2005; Czarniawska, 2013), gerando a ideia de rotina e ordem. Conforme observam Tsoukas e Chia (2002), nas abordagens tradicionais, a mudança é entendida como algo excepcional que deve ser evitado e corrigido.

Essa forma de entender as organizações continua hegemônica nos Estudos Organizacionais e possui grande representatividade nas publicações internacionais e nacionais (Duberley, Johnson \& Cassel, 2012; Vergara \& Caldas, 2005). No entanto, apesar do predomínio da forma reificada de pensar as organizações, a partir dos anos 1970, as relações objetividade e subjetividade começaram a ser questionadas, e a subjetividade e a dimensão qualitativa ganharam espaço nas teorias organizacionais (Duberley et al., 2012; Peci, 2003).

Questionamentos sobre os limites entre a organização e seu ambiente começaram a aparecer; ao mesmo tempo, esses modelos tradicionais não conseguiram explicar a turbulência a que algumas organizações estavam submetidas, devido à 
demanda por inovação e a necessidade de rápidas mudanças (Czarniawska, 2013; Weick, 1973).

Essas lacunas levaram autores (Czarniawska, 2013; Latour, 2011; Schatzki, 2005; Weick, 1973) a voltarem sua atenção para a perspectiva processual das organizações. Em 1969, Karl Weick publica The Social Psychology of Organizing, sugerindo que o termo organizações seja entendido como um verbo (Organizing), e não como um substantivo (Organization) (Weick, 1973; Weick, Sutcliffe \& Obstfeld, 2005).

É nesse aspecto que reside a principal ideia de Weick: organizações devem ser entendidas como processos que se criam, se conservam e se dissolvem. Ou seja, estudar os processos resulta em um retrato mais fiel do fluxo contínuo de ações que compõem as práticas organizacionais (Weick, 1973). Ver o mundo como um processo contínuo significa pensar as organizações como produto de processos que existem anteriormente à organização, e que a tornam possível (Bakken \& Hernes, 2006). Nessa perspectiva, a organização deve ser entendida como uma construção constante dos atores, de suas práticas e de suas interpretações do que estão fazendo (Czarniawska, 2008b), construída a partir das interações dos sujeitos, como um conjunto de ações inter-relacionadas (Bispo \& Godoy, 2014).

Weick (1973), quando escreve sobre comportamentos interligados, diz que são eles os elementos básicos constituintes de qualquer organização. Sem se preocupar em definir as organizações, o autor entende que estas são formadas por comportamentos repetitivos, recíprocos e contingentes, que se desenvolvem e são mantidos entre dois ou mais atores. Assim, uma organização é o resultado das atividades de seus membros, podendo ser compreendida como um sistema interpretativo (Daft \& Weick, 1984), portanto consiste em um sistema de significados. Weick (1995), tomando como ponto de partida o conceito de enactement, entende as organizações como criadoras de sentido, visto que o indivíduo é ativo no ambiente e, portanto, é capaz de modificar a si e ao ambiente (Weick, 1995), pois fazer sentido implica conectar o concreto ao abstrato (Weick et al., 2005). A compreensão de Weick $(1973,1995)$ não repousa nas definições de práticas; no entanto, para esse autor, a organização é resultado de um conjunto de atividades realizadas coletivamente por meio da interação dos diversos atores organizacionais.

Quem introduz uma ontologia das práticas sociais, segundo Santos e Silveira (2015), é Schatzki (1996, 2002, 2005), que entende que uma organização, como qualquer fenômeno social, é um conjunto de práticas e arranjos materiais, sendo as práticas um conjunto de atividades humanas organizadas em um espaço e tempo. Os arranjos materiais podem ser compostos por quatro tipos de entidades: os seres humanos, os artefatos, outros organismos e outros pertences (Schatzki, 2003). Ou seja, sempre que alguém age e, com isso, exerce uma prática, faz isso em um cenário que é composto por entidades materiais, portanto, os arranjos.

Assim, Schatzki $(2003,2006)$ entende que práticas são estruturadas em dois componentes básicos: ações e estrutura. A estrutura abarca quatro fenômenos principais: (1) entendimento das ações que constituem a prática; (2) regras, diretivas explícitas, advertências ou instruções que os participantes observam ou negligenciam na prática; (3) estruturação teleológico-afetiva (que engloba uma variedade de finalidades, projetos e ações que são aceitos ou impostos aos participantes); e (4) entendimento geral sobre a natureza do trabalho.

Para esse autor, uma organização é um conjunto de práticas e arranjos materiais, sendo preciso, para que a organização aconteça e se perpetue, a contínua performance dos atores. Nesse sentido, a organização é resultado de um conjunto de práticas e arranjos, um produto de ações performadas, uma malha que envolve as práticas (Schatzki, 2005). Isso implica que a organização aconteça quando suas práticas constituintes sejam realizadas, ou seja, quando sejam desempenhadas as ações que constituem a organização (Schatzki, 2006). Santos e Silveira (2015) ressaltam o caráter coletivo das práticas, pois, ainda que “as ações que compõem uma prática sejam desempenhadas por indivíduos, a organização dela, aquilo que lhe dá coerência - o seu conjunto de entendimentos, regras e estruturas teleoafetivas não pertence a um ou outro (ou mesmo a um grupo de indivíduo(s) específico(s))" (p. 83).

As práticas não são estáticas, mas podem se repetir ou se modificar, intencionalmente ou não (Cooper, 1992; Schatzki, 2005). É nesse sentido que a organização é entendida como um fluxo que é constantemente ordenado e reordenado por agentes (Czarniawska, 2013) que precisam criar um sentido de ordem, na tentativa de tornar o mundo estável, previsível e seguro. Sendo o mundo caótico, sempre em fluxo e transformação, o organizar envolve trazer ordem para o caos. É a atividade humana que forja a ordenação, gerando efeitos estáveis, reduzindo a complexidade. A organização é, portanto, resultado de uma estabilização artificial da incessante mudança, resultado do desejo de controlar, definir e estruturar. Para isso, é preciso que a complexidade seja diminuída, simplificada, fixando por um momento o que está em contínuo movimento (Clegg et al., 2005).

Estudar o organizing requer abandonar a ideia de que as organizações sempre existiram independentemente da ação humana e aceitar que é a ação que a torna possível (Czarniawska, 2008b). Para Tsoukas e Chia (2002), a organização passa a ser entendida como resultado de um processo que tem duas 
direções: a primeira, de que a organização é uma tentativa de ordenar o fluxo contínuo das ações humanas; a segunda, de que a organização é um padrão que é constituído, conformado e emerge da mudança, ou melhor, da tentativa de evitá-la.

Assim, organizações são abstrações que, devido às constantes modificações do organizar, estão sempre em um processo de se tornar, aliando, desse modo, uma parte da conformação anterior, e, devido às mudanças das práticas e dos atores, apresentam, com o tempo, novas conformações (Clegg et al., 2005). 0 constante processo de se organizar pressupõe a mudança contínua, logo os estudos são direcionados para o movimento entre continuidade e descontinuidade, entre constância e mudança, entre entidade e fluxo (Bakken \& Hernes, 2006).

Igualmente, nessa perspectiva, a imprevisibilidade é entendida como algo inerente, pois acontece na constante reinterpretação e ressignificação organizacional (Hatch, 1999). Somadas à imprevisibilidade, características como a ambiguidade, a incerteza e a equivocidade também são trabalhadas de modo diferente, pois elas não necessitam ser erradicadas e estabilizadas, como acontece em outras abordagens (Czarniawska, 2006; Schatzki, 2005).

A ambiguidade também acontece quando o que não é especificado - seja pela ausência de regras, pela discordância, incongruência ou constante mudança - gera múltiplas interpretações, havendo espaço para a criatividade e para a inovação. Esse constante reconstruir se relaciona à configuração organizacional anterior, mas traz novos componentes, podendo-se observar uma continuidade aliada a uma descontinuidade (Hatch, 1999).

A emoção também ganha destaque nessa abordagem, pois ela é vista como própria das relações humanas e, por esse motivo, indissociável da vida organizacional (Cornelissen, Mantere \& Vaara, 2014; Hatch, 1999; Weick et al., 2005). O humor, a descontração junto à colaboração e o compartilhamento de conhecimento mostram como a ordem, a normatividade do processo de gestão é permeada pela criatividade (Sawitzki \& Antonello, 2014). Além disso, a gestão e a criação, processos aparentemente antagônicos, mostram-se indissociáveis, pois o limite entre uma prática e outra é tênue; processos de gestão são guiados por ideias criativas e momentos de criação são gerenciados (Davel \& Vianna, 2012). Nessa perspectiva, o entendimento da organização como algo estritamente racional e cognitivo é questionado, dando espaço para a imprevisibilidade, ansiedade e, consequentemente, emotividade (Clegg et al., 2005).

Assim, as organizações são constantemente performadas, o que sugere a necessidade de abandonar a ideia de que elas sempre existiram (Czarniawska, 2006). Essas ações contínuas podem se manter ou se modificar, ou seja, as práticas não são estáveis (Cooper, 1992), sendo a mudança condição inerente da organização (Tsoukas \& Chia, 2002).

\section{PERCURSO METODOLÓGICO}

Por se mostrar apropriada para a descrição e análise das relações sociais, adotamos a abordagem qualitativa, já que aqui o foco reside nas práticas cotidianas e interações sociais. Esta pesquisa teve como objetivo geral compreender como um grupo de teatro se organiza, como resultado de práticas e processos, dessa maneira a pesquisa qualitativa mostrou-se apropriada, pois ela possibilita a compreensão do mundo social (Flick, 2002). Como estratégia de pesquisa, adotamos o estudo de caso (Yin, 2001), pois, por se tratar de um fenômeno contemporâneo, os dados devem consistir de entrevistas, observações e documentos, na tentativa de obter maior detalhamento do que é detectado (Strauss \& Corbin, 2008), com o intuito de analisar os atores, questioná-los e aprender suas práticas (Schatzki, 2005). Assim, é preciso ir até a organização e estar lá o máximo de tempo que for possível (Czarniawska, 2008a). Por conseguinte, quando o trabalho se caracteriza por sua natureza qualitativa e por sua perspectiva subjetiva, o shadowing, as entrevistas e os documentos são entendidos como um conjunto de fontes importantes para estudar as organizações por meio das interações cotidianas (Czarniawska, 2008a; Miller \& Dingwall, 1997; Vásquez, Brummans, \& Groleau, 2012).

Como objeto de pesquisa, escolhemos o Grupo Galpão, um grupo de teatro com sede em Belo Horizonte, fundado em 1982, contando mais de 30 anos de experiência nas artes cênicas (Souza \& Carrieri, 2011), tendo participado de mais de 110 festivais nacionais e internacionais, e acumulando mais de 100 premiações brasileiras (Grupo Galpão, 2014).

Para reunir material empírico, aplicamos três técnicas: shadowing, documentos e entrevistas. Utilizamos fontes documentais disponíveis na internet e no Centro de Memória do Galpão Cine Horto, - livros, teses, dissertações, revistas, recortes de jornais e filmagens que narram a trajetória do grupo, além de diários de montagem e cadernos escritos pelos integrantes, como relatos pessoais das apresentações, ensaios, workshops etc. Após quatro semanas de pesquisa documental, obtivemos um total de 110 páginas escritas a mão com excertos copiados desses materiais.

Aplicamos a técnica do shadowing durante 35 dias, totalizando 185 horas. Durante esse tempo, acompanhamos o grupo em seus ensaios, reuniões, apresentações, viagens e atividades administrativas. Aqui o shadowing ganha uma variação: em vez de acompanhar somente um integrante do grupo, 
como na maior parte dos estudos, acompanhamos todo o elenco e produção do grupo teatral em suas atividades. Assim, uma das características mais marcantes e distintivas do shadowing é mantida, que é sua qualidade de ser uma técnica dinâmica e itinerante (Czarniawska, 2008a; McDonald, 2005) produzindo material empírico pela observação direta e, por isso, considerada fonte primária. Essa observação gerou um diário de campo de 127 páginas no Microsoft Word.

Realizamos 16 entrevistas com integrantes de diversas áreas do grupo, as quais foram gravadas e transcritas na íntegra e, posteriormente, submetidas à validação interna (Flick, 2002), com intuito de atribuir maior fidedignidade ao material. Optamos por manter o anonimato dos entrevistados, atribuindo a eles um nome fictício, baseado nas obras de William Shakespeare.

Após as observações, entrevistas e transcrições, os dados foram analisados utilizando a Grounded Theory Construtivista (Charmaz, 2008). Desse modo, nossa análise deu-se por meio de um processo contínuo de codificação e recodificação, adotando-se códigos, e não categorias. Nessa tarefa, nos debruçamos sobre os dados diversas vezes, interagindo com eles, codificando e recodificando, levantando novas questões para o material coletado, questionando os dados e voltando a coletálos, quando necessário, conforme orientação de Charmaz (2008).

\section{O CONSTANTE ORGANIZAR DO GRUPO GALPÃO: DICOTOMIAS NAS INTERAÇÕES COTIDIANAS}

A sede do Grupo Galpão localiza-se na Rua Pitangui, na cidade de Belo Horizonte. Atualmente, o Grupo Galpão, juntamente ao Galpão Cine Horto, ocupa quatro espaços nessa mesma rua: o Galpão Cine Horto, onde acontecem cursos de teatro, apresentações teatrais, entre outras atividades; o Galpão do meio, onde ficam armazenados cenários e outros objetos; a Casa Rosada, onde funcionam as atividades financeiras; e o Grupo Galpão, onde acontecem os ensaios e uma parte das atividades administrativas, bem como as atividades de comunicação, produção e planejamento. Nossas observações se concentraram no último espaço listado (o Grupo Galpão), mas, em virtude de utilizarmos a técnica shadowing, que possui grande mobilidade, tivemos momentos de observação nos quatro locais.

Após o primeiro dia, e decorrido certo tempo de observação, foi possível notar que alguns eventos se repetem, e as observações atingem certo grau de saturação no que se refere aos hábitos e rotinas. Geralmente, as atividades do grupo se desenvolvem na parte da tarde. Alguns poucos funcionários da área administrativa trabalham pela manhã, já que o Grupo trabalha com o sistema de banco de horas, porém a maior parte das atividades se concentra entre 13 hoo e 19hoo. Por causa disso, mantivemos nossas observações, na maioria dos dias, entre esses horários.

\section{Quando as portas se fecham}

Geralmente, os atores chegam ao local de ensaio por volta das 14 hoo. Uma parte dos atores, ao chegar, se encaminha diretamente para a sala de ensaio. Outra parte, em geral aqueles que exercem funções administrativas, se movimenta pelos outros ambientes do imóvel, muitas vezes assinando papéis, marcando reuniões e discutindo pautas. Quando o horário marcado está se aproximando, todos entram na sala de ensaio.

Na maior parte das vezes, ao entrarem, os atores trocam de roupa, ensaiam com seus instrumentos individualmente, até que definam o que será feito conjuntamente. Algumas vezes, optam por um alongamento corporal ou por um aquecimento vocal; outras vezes, passam textos ou músicas coletivamente, ou em pequenos grupos. Ainda, ocasionalmente, discutem em conjunto o que farão, mas, na maioria das vezes, um deles já chega com uma ideia pronta.

A expressão "Vamos começar?" é rotineira, não só ao chegarem, mas, também, após o intervalo. Porém, identificamos que o marco para sinalizar que o ensaio começou é o fechamento das portas da sala de ensaio. Isso é um indicativo, para os atores e para as pessoas que trabalham do lado de fora, de que o ensaio começou e, portanto, não deve ser interrompido. Geralmente, o intervalo ocorre entre 17 hoo e 18 hoo, quando se abrem as portas da sala, indicando que poder haver interrupção. Nos intervalos, os atores fazem um lanche e é comum continuarem conversando sobre o que estão fazendo. As portas se abrem novamente por volta das 19hoo, que é o horário fixado para que o ensaio termine, e, próximo a esse horário, é possível perceber que os participantes se dispersam, e, aos poucos, saem.

Uma única pessoa transita entre as salas com maior frequência: Helena, que é a encarregada da limpeza e do café. Com exceção dela, ao se fecharem as portas, há um isolamento, uma divisão. As pessoas que ficam do lado de fora têm outras atividades, outra rotina. As funções desempenhadas por estas são entendidas como atividades de apoio, como aparece em uma entrevista: “Toda a área administrativa, produção, comunicação, que dá suporte à atividade artística, que, então, não é a área de fim do Galpão, que é produzir teatro, mas é a área meio que estabelece todas as condições para que o teatro seja 
produzido" (Laertes, entrevistado). A equipe de apoio tem uma carga de trabalho muito intensa e cada um controla o seu próprio horário. Suas funções e cargas horárias são, até certo ponto, definidas, mas, como o trabalho pode ser feito de maneira mais individualizada, cada um tem sua rotina.

Ao contrário dos atores, a equipe de apoio não tem um horário de lanche predefinido, cada um faz o seu lanche individualmente. Durante todos os dias, o lanche esteve lá, mas poucas foram as vezes que vimos a equipe lanchar, pois fica muito entretida com o trabalho. A maior parte desse trabalho é feita nos computadores e com o uso do telefone. Quando os atores abrem as portas da sala de ensaio, alguns integrantes da equipe de apoio entram para pegar assinaturas, tirar dúvidas, entregar ou informar algo. Reuniões acontecem semanalmente, quando as coordenações dessas áreas se reúnem. Em outra reunião, em que alguns atores participam, que é o conselho executivo (três atores, o gerente executivo e a coordenadora de produção), o gerente executivo leva pautas que não foram resolvidas na reunião de coordenação. Salvo essas duas, acontece, ainda, uma reunião, conhecida como $\mathrm{G}_{12}$, com os 12 atores, o gerente executivo e a coordenadora de produção.

\section{Tecendo práticas e arranjos}

Durante as entrevistas, foi possível perceber as práticas nas quais os agentes estão envolvidos, estabelecendo uma conexão com entidades materiais (Schatzki, 2006). No trecho a seguir, é possível identificar quais ações são entendidas como pertencentes a determinada prática: “Eu falei que era mais planejamento, é [...] que era exatamente essa coisa da busca do recurso, do planejamento do grupo, é [...] da relação com as empresas, da relação com o poder público" (Oswaldo, entrevistado). Assim, as ações de "buscar recursos”, cuidar do "planejamento do grupo" e se relacionar com as empresas e com o poder público são entendidas como práticas da área de Planejamento. Com o passar do tempo, houve uma maior divisão das funções no grupo, mas as próprias pessoas foram trabalhando para que essa divisão acontecesse, criando um entendimento de quais ações pertencem a determinada prática e mostrando que as regras delimitam, direcionam e censuram o que deve ou não ser feito por determinada pessoa (Santos \& Alcadipani, 2015; Schatzki, 2005).

Em todas as práticas observadas no grupo, os arranjos materiais estavam presentes, pois, sempre que alguém age, a ação se dá em um ambiente composto de entidades materiais (Schatzki, 2005). Quando Adriana e Hérmia, do Planejamento, conversam, observamos: “Adriana e Hérmia respondem e-mails, preenchem formulários. Discutem sobre planilhas, e Adriana fala: “Tô curtindo esse Salic novo”' (Diário de Campo - 30/9/2014). Durante o tempo todo há uma interação com o computador e seus sistemas, inclusive o sistema dos lançamentos que cabem ao Planejamento: o Salic.

As interações de práticas e arranjos são, muitas vezes, mediadas por conexões tecnológicas (Schatzki, 2005), e essas interações são modificáveis, podendo ser rearranjadas, como é o caso de inovações tecnológicas, por exemplo, relações que antes envolviam o fax, hoje, não envolvem mais. Além disso, os atores interagem a todo momento com os instrumentos, baús, ar-condicionado, cadeiras, entre outros. Segundo Schatzki (2003, 2005), os arranjos materiais podem ser compostos por quatro tipos de entidades: os seres humanos, os artefatos, outros organismos e outros pertences. A prática teatral está intimamente ligada com diversos objetos, como: instrumentos musicais, figurinos, o próprio galpão no qual ensaiam e tudo que está em seu interior.

Os layouts, a forma como os objetos estão organizados, igualmente, interferem nas convivências e nas práticas (Schatzki, 2005). Tudo que há dentro do galpão é manejável. A cada dia de observação, os objetos e mobiliário estavam em um lugar diferente, pois, quando uma prática é realizada, toda a conformação do espaço é modificada, de modo que torne o espaço propício para aquela determinada prática (Santos \& Alcadipani, 2015). Assim, dependendo das ações que desempenharão naquele espaço, toda a conformação da sala é alterada. Sempre que realizam reuniões, colocam a mesa no centro da sala de ensaio: “Havia uma mesa enorme no centro com cadeiras, como se houvesse acontecido uma reunião" (Diário de Campo - 26/8/2014).

Nesses casos, devido à reunião que iria acontecer, os atores colocam uma mesa e cadeiras no centro e, quando começa o ensaio, desmontam a mesa e as cadeiras e montam o que for preciso para ensaiar: "Modificam todo o espaço mudando os objetos e mobiliários de lugar para construir a conformação da peça" (Diário de Campo - 4/9/2014). Já quando se preparam para as turnês e viagens, colocam instrumentos e figurinos dentro dos baús para carregar o caminhão, e, quando retornam, voltam com tudo outra vez: “Ao entrar no galpão, percebo que os baús voltaram, foram colocados no galpão novamente. Bianca, Edgar e Horácio tiram instrumentos dos baús" (Diário de Campo - 3/10/2014).

Quando algum instrumento está danificado, a prática de atuar fica comprometida: "Em um momento do ensaio, a alça do acordeom que Adônis estava tocando arrebenta. Gertrudes pega outro acordeom em um baú. Discutem sobre levar os acordeons para consertar" (Diário de Campo - 22/5/2014). E, quando os instrumentos não estão disponíveis, muitas vezes, o ensaio é desmarcado. 
Muitos dos materiais são antigos e reutilizados nas apresentações. Ao longo do tempo, foram criados sentimentos afetivos com os materiais, pois muitos destes estão com eles durante todo o percurso do grupo. Alguns ganham até nomes ou apelidos, como no caso de um baú que acompanha a equipe técnica em todas as viagens: “Ao se referirem ao ‘Negão’: ‘Onde está o Negão?’, eu pergunto: ‘Quem é?’. E eles me respondem que é um baú. Um baú todo preto onde ficam várias ferramentas" (Diário de Campo - 11/10/2014). Outro exemplo é o carro (Veraneio) que acompanhou os atores durante a peça "Romeu e Julieta", tornando-se palco de encenação de toda a peça: "A Esmeralda, velha veraneio que se tornou nacionalmente conhecida na futura montagem de 'Romeu e Julieta', cinco anos depois" (Brandão, 2002, p. 56).

A organização é composta por um conjunto de práticas e arranjos materiais; por esse motivo, as pessoas interagem com os objetos em suas ações cotidianas, e a forma como esses objetos são arranjados e rearranjados se relaciona com as práticas executadas. Na tentativa de se ordenar o mundo, os objetos ganham funções estabelecidas, assim como as pessoas. Organizar é, também, atribuir sentido ao mundo, às pessoas, às relações e aos objetos.

A seguir, analisamos as quatro dicotomias observadas no constante organizar do Grupo Galpão.

\section{Informalidade X Formalidade}

As relações humanas, em sua forma mais cotidiana, são marcadas pela informalidade das ações e dizeres; em contrapartida, na tentativa de ordenar o fluxo contínuo das ações humanas e no desejo de controlar, definir e estruturar (Clegg et al., 2005; Tsoukas \& Chia, 2002), surgem certas formalizações. Além disso, a mudança organizacional é impulsionada e referenciada pelo passado da organização (Hatch, 1999).

No Grupo Galpão, uma busca pela formalidade é percebida desde o seu início:

Um dia antes de iniciarem a montagem de "E a noiva não quer casar”, Adônis, Cordélia, Vênus e Jorge reúnem-se em torno da mesa de um bar e decidem organizar-se jurídica e estruturalmente como um grupo, para desenvolver um trabalho de longo prazo [...] (Brandão, 2002, p. 28).

Vê-se que, na tentativa de manter um trabalho em longo prazo, os atores buscaram se organizar juridicamente e estruturalmente. Ou seja, as práticas de atuação já existiam anteriormente à organização (Weick, 1973), mas, cotidianamente executadas, foram se cristalizando e buscando consolidação na formalidade. Embora as práticas existissem, ainda não possuíam um espaço físico fixo onde o grupo pudesse manter sua rotina, mostrando que a organização não possui um vínculo espacial tão grande, pois é possível que ela exista sem um local fixo, somente como um conjunto de ações interrelacionadas (Schatzki, 2005), como uma construção constante dos agentes (Czarniawska, 2008b):

Na verdade, o Galpão se formou antes daquela ata de fundação - naturalmente [...] sem um local próprio para ensaiar - [...] Mais do que um espaço físico, posteriormente adquirido na rua Pitangui, o Galpão é uma disposição de ânimo, um estado de alma, uma coragem e uma utopia ávida de se fazer realidade (Brandão, 2002, p. 28).

Mesmo assim, os ensaios se realizavam e a organização acontecia, mostrando que sua existência está intimamente associada à perfomance dos agentes, ou seja, a organização é a performance das ações que as constituem, como as reuniões, os ensaios e a produção:

Não tínhamos sede, não tínhamos nada, a gente tinha, onde a gente reunia, podia ser um bar, podia ser uma sala lá da FAFICH, podia ser onde [...] uma praça, podia ser uma casa da gente (Vênus, entrevistada).

Ao longo do tempo, essa forma de se organizar menos padronizada, menos formal, é entendida pelos atores como insuficiente, amadora e um equívoco, e eles passam a buscar o controle, o "profissionalismo" ou, como salientaram Souza e Carrieri (2013), a "profissionalização”. Ao narrar a história do Grupo Galpão, Brandão (2002) diz: “Abandona-se definitivamente a ideia de direção coletiva e desenvolve-se um sentimento de profissionalismo, competência e eficácia fundamentais para um grupo que pretendia reanimar-se e elevar-se acima dos equívocos e amadorismos dominantes no teatro mineiro naquela época" (p. 51). No processo de resistir à mudança (Tsoukas \& Chia, 2002) e na tentativa de estruturar e estabilizar a incessante mudança (Clegg et al., 2005), o Grupo emerge. Ao tentar buscar a formalização e padronização, o Grupo se modifica, mas não em sua completude, se encontrando sempre no movimento entre continuidade e descontinuidade, entre constância e mudança (Bakken \& Hernes, 2006). Isto é, busca-se a formalidade, mas sem perder, totalmente, a informalidade: 
Então, o Galpão sempre foi muito informal, isso é muito bom, isso faz bem para a criação, mas essa informalidade, do ponto de vista da gestão, às vezes era uma loucura porque não tinha padrão para nada. Então é tudo muito solto, muito informal, hoje, há uma tentativa de formalização, por exemplo, de contratos, de carteiras, isso já vem de alguns anos, de assinar a carteira das pessoas, mas era um grau de informalidade, assim, falta de contrato, falta disso, então, hoje, o papel do Laertes [...] é de reduzir esse grau de informalidade, mas também sem perdê-la totalmente (Oswaldo, entrevistado).

A mudança passa a ser exigida pelos vínculos que o Grupo Galpão estabelece com outras organizações, por exemplo, com o poder público (Souza \& Carrieri, 2011). Mostrando que a organização não é uma entidade isolada, seus limites são fluidos (Cooper, 1992) e a mudança é contínua (Chia, 1997), pois as práticas se modificam e as malhas criadas entre agentes de organizações diferentes podem modificar ambas as organizações.

Atividades que antes não eram exercidas passam a fazer parte do cotidiano dessa organização. Assim, atuando conjuntamente, as organizações modificam-se umas às outras, as práticas de uma organização ligam-se às práticas de outras organizações, formando malhas e, ao longo do tempo, modificando-se mutuamente. Por fim, à medida que as práticas vão sendo repetidas e cristalizadas, e, na tentativa de controlar e estruturar, surgem as formalizações. Adicionado a isso, quando a informalidade é ligada à ideia de falhas, o Grupo passa a buscar formalidade. Mesmo sem um local fixo para ensaiar, é possível perceber que a organização é mantida pelo constante "performar" de suas práticas, oscilando entre formalidade e informalidade e, no intuito de estabilizar a mudança, a organização acontece, e, conjuntamente com outras organizações, vai se modificando.

\section{Fragmentação X Centralização}

Juntamente à busca de uma maior formalidade, foi possível perceber que o Grupo Galpão buscou se departamentalizar e setorizar, definindo funções e centralizando atividades que anteriormente se encontravam fragmentadas. Dessa forma, oscila entre uma fragmentação de tarefas, uma organização onde todos fazem um pouco de tudo, e uma organização onde as tarefas são anteriormente definidas. Nas entrevistas, uma das atrizes descreve como se organizavam anteriormente: "E aí, como nessa época da fundação a gente fazia, não tinha muito funções definidas, definidas assim, todo mundo fazia de tudo, dava palpite em tudo, reunia-se pra tudo" (Vênus, entrevistada).

Hoje, nas entrevistas, é perceptível uma busca por centralidade, em que cada pessoa deve possuir funções bem delimitadas:

Então isso aí, agora hoje isso tá bem mais claro, a gente ainda não tem um descritivo de funções, de atribuições e funções assim no papel, a gente não conseguiu chegar nisso, eu acho que a gente vai conseguir chegar nisso, eu quero, eu tenho esperança, [...] Por isso que eu falo pra você que é melhor assim, é mais claro, é mais claro assim: 0 que que a Comunicação tem que fazer, o que que tá na mão do Planejamento, quem que faz o quê, entendeu? E é mais fácil da gente cobrar e se der errado, [...] Então isso daí eu acho que nossa, hoje é um paraíso nesse sentido (Emília, entrevistada).

Para isso, a organização se espelhou em uma gestão empresarial, contudo busca-se manter um pouco da essência do grupo ou, como alguns integrantes da organização concluem, que a essência não seja modificada. No entanto, há um claro movimento de incorporação de práticas de gestão no fazer artístico do grupo (Oliveira \& Cavedon, 2013). Logo, organizando-se e reorganizando-se, tende-se a modificar práticas e estruturas, sem, no entanto, modificar toda a conformação, pois trabalha-se com a estrutura preexistente (Hatch, 1999):

Difícil dizer, porque o Galpão é uma associação, mas tem toda uma estrutura e um formato de uma empresa comum mesmo. [...] Eu vejo a estrutura do Galpão como uma empresa mesmo, com todos os elementos que teria. Eu não sei o que que define (Ricardo, entrevistado).

Essas características são consideradas uma marca do grupo, pois relacionam essa forma de se organizar com a própria concepção de arte e de artístico. Isso mostra como a gestão e a criação estão intimamente ligadas e que há uma interdependência entre as duas nas práticas organizacionais (Davel \& Vianna, 2012):

Porque tá ligado a criação, e a criação não é algo, às vezes, necessariamente palpável e pragmático [...] a criação, ela tem uma outra lógica, né, assim, de acontecer [...] Então, eu acho que eles 
refletem um pouco essa desorganização criativa pro lado de lá e eu acho que a gente, também, reflete um pouco pro lado de cá, puxando e tudo (Ofélia, entrevistada).

Mesmo assim, a setorização é entendida como condição para o bom funcionamento da organização, sendo essa divisão uma característica que marca o que é ou não uma organização. Assim, fica visível que a centralização de funções, em determinado cargo ou pessoa, aconteceu com o passar do tempo, em uma contínua tentativa de ordenar (Clegg et al., 2005):

Eu [...] acho que tem que setorizar mesmo, não tem jeito, [...] a Emília não tem condição de vender espetáculo para todos os festivais, se ela tiver que sentar no computador e ficar montando condição, não é isso, ela tem que gerenciar mesmo, delegar, falar: "Oh, Catarina, você tem que fazer isso pra mim, faz esse contrato". (Catarina, entrevistada).

Mesmo que esse movimento de centralizar as funções gere uma sensação de simplificação, as práticas são constituídas de complexidade e heterogeneidade (Cooper, 1992). Desse modo, os depoimentos mostram que o Grupo é uma construção constante dos agentes, de suas práticas e de suas interpretações do que estão fazendo (Czarniawska, 2008b). No entanto, com o passar do tempo, as funções vão se reorganizando e se redividindo, mostrando que a imobilidade é uma falácia (Clegg et al., 2005), pois as práticas não são estáticas e podem ou não se repetir (Schatzki, 2005).

Também há uma oscilação nessa dicotomia: busca-se uma centralização das atividades, uma departamentalização, características que, segundo eles, são similares às de uma empresa. Contudo, entendem que uma associação se difere de uma organização empresarial:

Então, eu acho que é uma fusão assim, essa coisa meio hibrida de ser uma associação mas com, não vou dizer com anseios de uma empresa, mas que tem características também de uma empresa, que tem algumas hierarquias, mas que são hierarquias só para que haja uma organização, não porque aqui se pense de uma forma, é... De uma forma vertical, né? (Ofélia, entrevistada).

Enfim, ao buscar a criação de departamentos, cargos e funções preestabelecidas, os agentes se reorganizam, mudando a configuração das relações e das práticas, com o intento de distanciar da forma anterior pela qual se organizavam. No entanto, não pretendem perder a essência do grupo, estando fortemente arraigada a ideia de que a fragmentação está relacionada à criação e ao artístico. Nesse sentido, tentam criar padrões, ordenar as práticas, gerando uma sensação de estabilidade, quando, na verdade, há complexidade e movimento.

\section{Horizontalidade X Verticalidade}

A terceira dicotomia que analisamos é a horizontalidade versus a verticalidade. Desde o primeiro contato com o Grupo, ao conversar com um dos funcionários, fomos alertados sobre a horizontalidade do Grupo. A ideia de que os 12 atores têm voz ativa é algo propagado não somente dentro da organização, mas, igualmente, para as pessoas que buscam contato com o Grupo. Em uma das conversas informais que tivemos com uma das funcionárias, ela disse:

Todos participam das decisões, a reunião de G12 é bem democrática. Perguntei a ela se ela participava, ela disse que não. Então, perguntei como ela sabia, ela respondeu que já havia ouvido a Gertrudes falar sobre isso em uma visita guiada com estudantes (Diário de Campo $-2 / 10 / 2014)$.

Ou seja, a horizontalidade, a tomada de decisão de maneira coletiva, é entendida como uma característica marcante do Grupo:

O grupo sempre foi uma coisa muito horizontal e de decisões colegiadas, esse é um traço do Grupo Galpão que é muito importante. [...] Então, o Galpão decide as coisas coletivamente, que é o que eles chamam hoje do G12. São os 12 atores, as decisões são coletivas e por isso mais consistentes (Oswaldo, entrevistado).

O Grupo Galpão surgiu em uma iniciativa de quatro pessoas e, com o passar do tempo, foi crescendo e se modificando. Durante esse período, foram se estabelecendo tarefas, dividindo funções e criando cargos, como discutido no tópico anterior. A criação de cargos acontece na tentativa de criar um sentido de ordem, tentando tornar o mundo estável, previsível e seguro (Clegg et al., 2005), ou seja, gerando uma estabilização das práticas, sabe-se a quem se reportar e quem é responsável pelo quê.

Apesar da suposta horizontalidade, vários indícios mostram que há uma verticalidade no grupo, que há lideranças 
estabelecidas e que o nível de participação nas decisões é um indicativo da posição nessa linha hierárquica. Embora os 12 atores sejam sócios, na reunião do conselho executivo, entendido como a alta cúpula do Grupo, somente três atores participam, além do gerente executivo e da coordenadora de produção. Quando perguntamos como foram escolhidas as pessoas que participariam dessa reunião, Oswaldo respondeu:

Foi muito espontânea. [...] 0 conselho artístico, por exemplo, se alguém quiser participar da reunião, alguns dos atores, a hora que quiser. 0 conselho executivo são aquelas pessoas ali, mas tem a reunião do G12 também, então tem uma dinâmica de reuniões com a própria equipe, coisas que não existiam até pouco tempo (Oswaldo, entrevistado).

Afora essas duas reuniões, há uma reunião de coordenadores com o gerente executivo, da qual não participa nenhum ator. Alguns membros não participam de nenhuma reunião, possuindo uma baixa participação nas decisões do grupo. Ou seja, no Grupo Galpão, o envolvimento com a participação nas decisões é um marco hierárquico. Mesmo que a horizontalidade seja uma característica que eles tentem alimentar, ao manterem o G12 e algumas decisões colegiadas, é possível perceber que há hierarquias silenciosas: “Disse que há uma tentativa de ser democrático, mas há sempre alguns que são mais persuasivos, que sempre existem as hierarquias silenciosas, por exemplo, o Adônis, é uma voz que todo mundo escuta, segundo ela" (Diário de Campo - 2/10/2014).

Sendo a organização um fluxo contínuo de práticas, as lideranças, igualmente, são resultado de processos que se criam, se conservam e se dissolvem (Czarniawska, 2008b). A prática de se reunir e de tomar decisões é entendida como uma característica que atribui hierarquia. A criação de cargos que atribuem responsabilidade às pessoas, também, confere um entendimento de pertencimento de poder.

O Adônis é que deu essa definição há um tempo atrás, que é a coordenação dos projetos especiais do Galpão; ele assina a direção artística, o Horácio, a direção administrativa, e eu assinaria a direção de projetos especiais do Galpão (Cláudio, entrevistado).

No Grupo Galpão, mesmo que os atores não cuidem mais da parte executiva, os funcionários se reportam a eles. As decisões continuam passando pelos atores, principalmente pelos três atores que participam do Conselho Executivo. Desse modo, no constante organizar das práticas, o grupo busca manter a horizontalidade, mas, em alguns momentos, tende à verticalidade, sempre oscilando entre os dois polos. As lideranças são definidas no constante reorganizar das práticas, pois, ao se atribuírem cargos e funções a determinadas pessoas, retiram-lhes ou thes conferem participação nas decisões. Quanto maior a participação nas decisões, maior o posicionamento na hierarquia, sugerindo um constante pêndulo entre horizontalidade e verticalidade.

\section{Recolhimento X Expansão}

Outro claro movimento organizacional presente no Grupo Galpão é seu constante recolhimento e expansão. Nesse sentido, os limites organizacionais são questionados, pois há uma variedade de pessoas que participam do processo organizacional, direta ou indiretamente.

Durante seu histórico, o Grupo Galpão escolhe, às vezes, trabalhar com um elenco menor e uma direção interna, e, outras vezes, com atores e diretores convidados. Atualmente, o Grupo opta por manter funcionários para as áreas administrativas e por trabalhar com consultores em determinadas áreas, quando, em alguns momentos, optou por uma organização em que os próprios atores desempenhassem, inclusive, as funções administrativas.

Diversas outras organizações estão atreladas às práticas cotidianas do grupo, formando uma infinidade de práticas interligadas. Como exemplo, Hérmia fala sobre suas funções: “Diz que sua responsabilidade é fazer a interlocução com o Ministério da Cultura, órgãos oficiais de cultura e parceiros. Além da elaboração de projetos e captação de novos patrocinadores e financiamentos" (Diário de Campo - 1/10/2014). Isso mostra a conexão do Grupo Galpão com outras organizações.

Outro exemplo reside nas funções de Ofélia: "Fala sobre a interface com os fornecedores, fotógrafos, videomakers, matérias de rádio e TV, divulgação, produções locais, como vender a imagem do grupo e preocupações com como divulgar" (Diário de Campo - 2/10/2014).

No intercâmbio entre se expandir e se recolher, há diversas características, por exemplo, a expansão se torna onerosa:

[...] o grupo foi crescendo, acho que as necessidades foram crescendo, a gente começou a ter mais funcionários. A gente conseguiu patrocínio, primeiro do Credireal, foi o primeiro patrocínio que a gente teve, então assim, é... As coisas foram mudando muito rapidamente. Então, o que era um grupo muito doméstico, onde a gente resolvia tudo, não tinha uma demanda de trabalho tão 
grande, também, passou a ser essa empresa hoje com tantos funcionários e tudo, e que não deixa a gente viver sem o patrocínio (Edgar, entrevistado).

Ao se expandir, o Grupo precisa de mais subsídio para arcar com seus custos. Somente a venda de espetáculos inviabiliza a manutenção dos funcionários atuais. Consequentemente, se tornam reféns da busca de recursos externos, sendo, então, necessário que se criem cada vez mais malhas, com outras organizações, no sentido de manter o funcionamento do Grupo, sendo este seu principal desafio atualmente.

Em contrapartida, o recolhimento gera conflitos. Ao longo da trajetória do Grupo Galpão, diversas vezes tentaram manter um grupo menor, coeso. Algumas vezes, o recolhimento foi uma alternativa, outras, um recurso para sobreviver, pois, no início, vários integrantes, diante de um fracasso, saíam do grupo.

Apesar de o grupo frequentemente se descrever como composto por 12 atores, o número de pessoas que participam da organização é incontável e oscilante. Isto é, com a constante mudança dos agentes que participam da organização, esta está sempre se reconfigurando (Hatch, 1999; Schatzki, 2005).

Uma das características mais sublinhadas do grupo é a de sermos um coletivo de atores, sem um diretor fixo. Isso traz como consequência uma natureza cambiante, heterogênea e bastante suscetível às transformações e à variedade [...] 0 grupo vive uma dialética permanente entre recolher-se e expandir-se (Moreira, 2013, p. 117).

Com a constante mudança, os laços nunca se tornam estáveis, podendo ser diferentes (Schatzki, 2005), como ocorre no cotidiano do Grupo Galpão. E o fluxo é constantemente ordenado e reordenado (Czarniawska, 2013), o que pode ser ilustrado pela substituição de atores.

Dessa forma, a organização é o resultado de uma estabilização artificial da incessante mudança que, aliando uma parte da conformação anterior, apresenta, com o tempo, novas conformações (Clegg et al., 2005), salientando a sua condição temporária (Hatch, 1999). Porém, as mesmas práticas repetidas diariamente, com certa constância, passam a sensação de ordem (Tsoukas \& Chia, 2002), gerando uma ideia de estabilidade:

Nessa época, eu era um ator convidado, durante alguns anos eu fiquei como ator convidado, acho que até depois do "Romeu e Julieta” eu passei a fazer parte do grupo, como um dos sócios assim [...] Eu acho que a minha história é muito bonita, eu acho que, assim, eu tenho um orgulho enorme de fazer parte do Galpão (Edgar, entrevistado).
Assim, a organização é permeada por diversos agentes que constroem conjuntamente esse cotidiano de práticas. A configuração da organização se torna, então, sempre cambiante. Porém, as práticas repetidas cotidianamente ganham certa constância e estabilizam a mudança, gerando a ideia de um grupo conciso e fechado.

\section{DISCUSSÃO}

A análise das oito categorias que integram as quatro dicotomias permite compreender a organização em uma perspectiva processual, o que nos leva a pensar sobre em que consistem as organizações. Em uma organização, ao se formalizarem práticas, padronizá-las e controlá-las, estabelece-se um conjunto de práticas que se agregam. Ao centralizar funções, estabelece-se uma determinada função a uma pessoa e, consequentemente, um determinado conjunto de práticas. Assim, cada função possui um conjunto de práticas a serem executadas, práticas que se agruparam, ou seja, ao se formalizar, centraliza-se e, ao se centralizar, formaliza-se. Quando se confere a uma determinada pessoa um conjunto de práticas, ela passa a ter, então, a responsabilidade sobre a execução dessas práticas e, consequentemente, a responsabilidade por essas práticas, e, mais uma vez, a formalização gera centralização e gera um lugar na hierarquia. Ao localizar determinada pessoa na hierarquia, ocorre a verticalização ou horizontalização dessa organização. Se as práticas conformadas sugerirem que existe a necessidade da contratação de uma nova pessoa, a organização se expande.

Assim, as quatro dicotomias estão relacionadas entre si, pois, ao contratar uma nova pessoa, atribuir funções a ela, responsabilizá-la por essas funções e identificar onde ela está na hierarquia, todos esses movimentos geram mudança e novas conformações organizacionais. Quando se tem a fragmentação das atividades, das práticas organizacionais, tem-se também uma maior informalidade, porque as funções estão distribuídas e são assumidas por todos, assim, a hierarquização vai depender de como as lideranças vão ser conformadas na divisão informal das tarefas. Se todos os integrantes fazem um pouco de tudo e um agente tem acúmulo de funções, a organização pode ser mais enxuta, pode haver um recolhimento. Quando há uma maior necessidade de dividir tarefas, especializar funções, criam-se novos cargos, contribuindo para a expansão organizacional.

A ausência de limites organizacionais, também, influencia a conformação do grupo. Ao entrar em contato com outras organizações, com pessoas de outras organizações, modificam-se as práticas, pois os membros podem ser 
pressionados a adotar procedimentos mais rigorosos, como no caso que envolve legislações. Ao sofrer pressões de outras organizações, a organização precisa definir quais práticas são importantes que os atores executem, formalizando seu trabalho, centralizando determinadas funções às pessoas, determinando responsabilidades que devem cumprir; ao mesmo tempo, já se confere ao novo membro um determinado grau de participação nas decisões, verticalizando ou horizontalizando a estrutura. Consequentemente, as lideranças, também, são resultados de práticas e processos.

A criação de determinadas práticas, também, é resultado de dicotomias, por exemplo, quando se quer centralizar mais as decisões, cria-se ou mantém-se um cargo na parte superior da hierarquia; de outro modo, para tomar decisões mais colegiadas, cria-se uma rotina de reuniões. A rotina de reuniões que o Grupo Galpão tem hoje não existia antes da chegada do Gerente Executivo, porém, como foi constatada a ausência de um cargo de gestão executiva, ele foi contratado (expansão) e foi colocado em uma posição da hierarquia (verticalização); posteriormente, ele centralizou atividades e funções e, como consequência, criou uma rotina de reuniões, criou uma prática que agora faz parte de sua lista de atividades e responsabilidades, que é gerenciar reuniões.

As dicotomias analisadas neste artigo corroboram a ideia de que as organizações não são entidades fixas, o que vai ao encontro do entendimento dos diversos autores (Bakken \& Hernes, 2006; Clegg et al., 2005; Czarniawska, 2013; Hatch, 1999; Latour, 2011; Schatzki, 2005; Tsoukas \& Chia, 2002; Weick, 1973) a que recorremos para entender o Grupo Galpão a partir dos seus processos. Nossa compreensão sobre o Grupo Galpão é justificada, ainda, pelos argumentos de Weick (1973, 1995) quanto às organizações serem melhor entendidas como verbo (organizing), isto é, nossa análise, ao privilegiar o que os membros do Grupo fazem coletivamente, vimos que o Grupo trata-se de um resultado do organizar, isto é, são realidades que resultam de um movimento constante de práticas e processos.

\section{CONCLUSÃO}

Depois de oito meses de pesquisa sobre o Grupo Galpão (em sites, livros, observações in loco, vídeos, transcrições de entrevistas), todo o corpus de material empírico acabou por criar uma fotografia, a qual, em nossa mente, é a de um ateliê coletivo. Nesse local, tipicamente, encontramos uma diversidade de materiais, no entanto é um espaço com um visual cheio de personalidade e com ar aconchegante. 0 ateliê deve ser pensado para ser prático e fácil de manter sempre organizado, porém, ao mesmo tempo, é comum o acúmulo de coisas nesses lugares, conferindo-lhe um ar de espaço para criatividade. Na composição da fotografia, podemos distinguir quatro elementos principais: uma prateleira ao longo da parede com materiais diversos e coloridos (informalidade e formalidade); uma mesa de trabalho dobrável (recolhimento e expansão); uma luminária pendente no canto (fragmentação e centralização); uma poltrona-cadeira decorativa (horizontalidade e verticalidade). É nesse espaço que diversos artesãos tecem suas práticas, a partir de interações e ações.

No entanto, entendemos que toda e qualquer forma de explicar e didatizar práticas organizacionais já traz em si reduções e limitações, pois abarcar toda a complexidade organizacional não é possível, e, ao trazer para o papel a fração vivenciada, também, se reduzem as experiências vividas em temáticas e eventos reincidentes. Assim, ressaltamos os principais pontos da análise de resultados, tendo em vista que esses pontos são uma pequena parcela da experiência vivenciada, que corresponde a uma parte menor ainda das práticas organizacionais.

Organizar é criar e atribuir sentido às ações, pessoas e objetos. Uma organização só é possível quando os agentes atribuem sentido às suas práticas e se relacionam com outros agentes e, conjuntamente, interagem atribuindo significado ao mundo, às pessoas e aos objetos. Assim, pensar a organização é pensar seus processos, seus agentes e suas interações.

No constante organizar das práticas, o grupo se configura e reconfigura. Durante a pesquisa, nos ativemos a quatro dicotomias que se relacionam entre si: informalidade $X$ formalidade; fragmentação $X$ centralização; horizontalidade $X$ verticalidade; e recolhimento $X$ expansão. Assim, a organização oscila entre essas dicotomias, mas faz tudo isso conjuntamente e ao mesmo tempo, pois busca a formalização dos processos, bem como a centralização das funções, ao mesmo tempo que tenta manter certo grau de informalidade e fragmentação, consideradas características marcantes do grupo. 0 grupo tenta manter a horizontalidade e as decisões colegiadas, mesmo que as consultorias realizadas identifiquem a ausência de hierarquias e a necessidade da contração de um gestor executivo que acabe por verticalizar a organização. Chamamos a atenção para o fato de que, ao analisarmos a organização como um todo, encontramos diferenças nas práticas e processos quando olhamos para as distintas áreas: administrativa e de criação. Isso era esperado, visto que a área administrativa tende a ser mais formalizada e centralizada, em virtude de sua natureza tendendo à burocracia.

Esta pesquisa contribui por voltar seu olhar para um objeto de pesquisa ainda pouco estudado pela Administração, 
os grupos teatrais, mas de grande relevância sociocultural. Adicionado a isso, a pesquisa soma ao questionar as formas mais tradicionais de estudar organizações, ampliando, assim, estudos brasileiros sobre a temática e contribuindo com o debate. Ao enfatizamos a natureza processual da organização, há uma mudança epistemológica na concepção do entendimento de organizações, pois elas deixam de ser entendidas como meios para atingir determinados fins e passam a ser um constante processo de atribuir sentido e organização ao fluxo dos acontecimentos. Além disso, os estudos teóricos e, principalmente, empíricos sobre organizing são escassos no contexto brasileiro, bem como a utilização do shadowing como fonte de material empírico.

Nossa pesquisa facilita o entendimento do modo como as organizações são criadas e recriadas a partir das práticas constantes e do resultado de processos, contribuindo com o conhecimento sobre o modo como as organizações acontecem, e não como elas simplesmente são. A própria conformação da prática teatral possui muitas especificidades, por isso, quando a essa forma de se organizar é lançado um olhar que rompe com os preceitos tradicionais da Administração, é possível perceber como a organização emerge. 0 limite organizacional é constantemente questionado, seja pelas interações com os espectadores, seja pelas interações com os espaços de apresentação. A partir dessa compreensão de organização, que não é uma entidade, mas, sim, cotidianamente construída por seus agentes, conferem-se a ela características inerentes às interações sociais, como a mudança, emoção e imprevisibilidade.

Outra contribuição desta pesquisa reside em entender a organização de um grupo teatral brasileiro de destaque internacional como um fluxo constante e ilimitado de práticas, focando sua natureza processual. Assim, o constante reorganizar das práticas teatrais permite que a própria organização se modifique e se reinvente, sem ficar presa a planejamentos fixos, possibilitando que o cotidiano das interações sociais molde as configurações organizacionais. Tendo em vista a importância das organizações na atualidade e o número expressivo de organizações culturais e artísticas, é possível perceber que as formas organizacionais, em suas interações com as pessoas, se modificam e, consequentemente, modificam as interações interpessoais.

Para ampliar o conhecimento sobre o tema, sugerimos incluir na agenda de pesquisa estudos em organizações formais e tradicionais, como pequenas e médias empresas, com o objetivo de compreender as dicotomias identificadas nesta pesquisa.

\section{NOTA DE AGRADECIMENTO}

Manifestamos nossos agradecimentos aos revisores pelos comentários construtivos que contribuíram para a versão final do nosso texto.

\section{REFERÊNCIAS}

Bakken, T., \& Hernes, T. (2006). Organizing is both a verb and a noun: Weick meets Whitehead. Organization Studies, 27(11), 1599-1616. doi:10.1177/0170840606068335

Bispo, M. S., \& Godoy, A. S. (2014). Etnometodologia: Uma proposta para pesquisas em estudos organizacionais. Revista de Administração da UNIMEP, 12(2), 108-135. doi:10.15600/1679-5350/ rau.v12n2p108-135

Brandão, C. (2002). Grupo Galpão: 15 anos de risco e rito. Belo Horizonte, MG: 0 grupo.

Charmaz, K. (2008). Construcionism and the grounded theory method. In J. A. Holstein, \& J. F. Gubrium, Handbook of constructionist research. New York, USA: Guilford Press.

Chia, R. (1997). Thirty years on: From organizational structures to the organization of thought. Organization Studies, 18(4), 685-707. doi:10.1177/017084069701800406

Clegg, S., Kornberger, M., \& Rhodes, C. (2005). Learning/Becoming/Organizing. Organization,12(2), 147-167. doi:10.1177/1350508405051186

Cooper, R. (1992). Systems and organizations: Distal and proximal thinking. Systems Practice, 5(4), 373-377. doi:10.1007/BFo1059829

Cornelissen, J., Mantere, S., \& Vaara, E. (2014). The contraction of meaning: The combined effect of communication, emotions, and materiality on sensemaking in the stockwell shooting. Journal of Management Studies, 51(5), 699-736. doi:10.1111/joms.12073

Czarniawska, B. (2006). A golden braid: Allport, Goffman, Weick. Orga nization Studies, 27(11), 1661-1674. doi:10.1177/0170840606068344

Czarniawska, B. (2008a). Organizing: How to study it and how to write about it. Qualitative Research in Organizations and Management: An International Journal, 3(1), 4-20. doi:10.1108/17465640810870364

Czarniawska, B. (2008b). A theory of organizing. Massachusetts, USA: Edward Elgar.

Czarniawska, B. (2013). Organizations as obstacles to organizing. In D. Robichaud, \& F. Cooren, Organization and organizing: Materiality, agency and discourse. New York, USA: Routledge.

Daft, R., \& Weick, K. (1984). Toward a model of organizations as interpretation systems. Academy of Management, 9(2), 284-295. doi:10.5465/AMR.1984.4277657

Davel, E., \& Vianna, L. G. L. (2012). Gestão-criação: Processos indissociáveis nas práticas de um teatro baiano. RAP-Revista de Administração Pública, 46(4), 1081-1099. 
Duberley, J., Johnson, P., \& Cassell, C. (2012). Philosophies underpinning qualitative research. In G. Symon, \& C. Cassell, Qualitative organizational research: Core methods and current challenges. Los Angeles, USA: SAGE.

Flick, U. (2002). Entrevista episódica. In M. W. Bauer, \& G. Gaskell, Pesquisa qualitativa com texto, imagem e som: Um manual prático. Petrópolis, RJ: Vozes.

Grupo Galpão. (2014). Portal Eletrônico Grupo Galpão. Recuperado de http://www.grupogalpao.com.br/port/home/

Hatch, M. J. (1999). Exploring the empty spaces of organizing: How improvisational jazz helps redescribe organizational structure. Organization Studies, 20(1), 75-100. doi:10.1177/0170840699201004

Latour, B. (2011). “What's the story?” Organizing as a mode of existence. In J. Passoth, B. Peuker, \& M. Schillmeier, Agency without actors? New approaches to collective action. London, UK: Routledge.

McDonald, S. (2005). Studying actions in context: A qualitative shadowing method for organizational research. Qualitative Research, 5(4), 455-473. doi:10.1177/1468794105056923

Miller, G., \& Dingwall, R. (1997). Context and method in qualitative research. London, UK: SAGE.

Moreira, E. L. (2013). Teatro, crise e renovação. Revista Subtexto, (10), 117-128.

Morgan, G. (1980). Paradigms, metaphors, and puzzle solving in organization theory. Administrative Science Quarterly, 25(4), 605 622. doi:10.2307/2392283

Oliveira, J. S., \& Cavedon, N. R. (2013). Micropolíticas das práticas cotidianas: Etnografando uma organização circense. RAE-Revista de Administração de Empresas, 53(2), 156-168. doi:10.1590/So03475902013000200004

Peci, A. (2003). Estrutura e ação nas organizações: Algumas perspectivas sociológicas. RAE-Revista de Administração de Empresas, 43(1), 24 35. doi:10.1590/So034-75902003000100004

Santos, L. L. S., \& Alcadipani, R. (2015). Por uma epistemologia das práticas organizacionais: A contribuição de Theodore Schatzki. Organizações \& Sociedade, 22(72), 79-98. doi:10.1590/1984-9230724

Sawitzki, R. C., \& Antonello, C. S. (2014). Em cena e nos bastidores: Processos de aprendizagem de um grupo de trabalhadores de uma organização do terceiro setor. Revista Alcance, 21(4), 719-748. doi:10.14210/alcance.v21n4.p719-748

Schatzki, T. (1996). Social practices: A Wittgensteinian approach to human activity and the social. Cambridge, UK: Cambridge University Press.
Schatzki, T. (2002). The site of the social: A philosophical exploration of the constitution of social life and change. University Park: The Penn State University Press.

Schatzki, T. (2003). A new societist social ontology. Philosophy of the Social Sciences, 33(2), 174-202. doi:10.1177/0048393103033002002

Schatzki, T. (2005). The sites of organizations. Organization Studies, 26(3),465-484. doi:10.1177/0170840605050876

Schatzki, T. (2006). On organizations as they happen. Organization Studies, 27(12), 1863-1873. doi:10.1177/0170840606071942

Souza, M. M. P., \& Carrieri, A. P. (2011). Racionalidades no fazer artístico: Estudando a perspectiva de um grupo de teatro. RAE-Revista de Administração de Empresas, 51(4), 382-395. doi:10.1590/So03475902011000400006

Souza, M. M. P., \& Carrieri, A. P. (2013). A arte de (sobre)viver coletivamente: Estudando identidade do Grupo Galpão. Revista de Administração da Universidade de São Paulo, 48(1), 7-20. doi:10.5700/rausp1070

Strauss, A., \& Corbin, J. (2008). Pesquisa qualitativa: Técnicas e procedimentos para o desenvolvimento de teoria fundamentada. Porto Alegre, RS: Artmed.

Tsoukas, H., \& Chia, R. (2002). On organizational becoming: Rethinking organizational change. Organization Science, 13(5), 567-582. doi:10.1287/orsc.13.5.567.7810

Vásquez, C., Brummans, B. H. J. M., \& Groleau, C. (2012). Notes from the field on organizational shadowing as framing. Qualitative Research in Organizations and Management: An International Journal, 7(2), 144-165. doi:10.1108/17465641211253075

Vergara, S., \& Caldas, M. (2005). Paradigma interpretacionista: A busca da superação do objetivismo funcionalista nos anos 1980 e 1990. RAE-Revista de Administração de Empresas, 45(4), 66-72. doi:10.1590/So034-75902005000400006

Weick, K. (1973). A psicologia social da organização. São Paulo, SP: Edgard Blucher.

Weick, K. A. (1995). Sensemaking in organizations. London, UK: SAGE.

Weick, K., Sutcliffe, K., \& Obstfeld, D. (2005). Organizing and the process of sensemaking. Organization Science, 16(4), 409-421. doi:10.1287/ orsc. 1050.0133

Yin, R. K. (2001). Estudo de caso: Planejamento e métodos (2. ed.). Porto Alegre, RS: Bookman. 